\title{
Analysis on Users' Emotions Through Comments on Weibo Based on Integrated Crisis Model
}

\author{
Haolong $\mathrm{Yu}^{1, *}$ \\ ${ }^{1}$ Communication Department, International College Beijing, University of Colorado Denver, Beijing 100083, \\ China \\ "Corresponding author. Email: haolong.yu@ucdenver.edu
}

\begin{abstract}
China and the Indian military force got an encounter on Galwan Valley border in mid-June 2020. Global Times, as a traditional press media platform but has finished online transformation successfully, posted an editorial through its Weibo account, "India retreats from deals with China: Global Times editorial" [1]. Weibo users were then activated on to the discussion to this event and left comments to this Weibo post to share their feelings and opinions. These comments, after being examined, were found deeply involved with emotions expressed via Weibo. It would be worthy to analyse this phenomenon as a glance of the agenda about emotions on social media. The paper focused on the emotional layer of comments to this post by social media users and tried to analyse what types of emotions may be expressed online by them in a crisis. Whether the social media exert an influence on users' emotions? The author took content analysis and qualitative research method as the way for conducting this study. Besides, the integrated crisis model and its revised version were used as the basis of sample processing [2] [3]. Each comment to the editorial on Weibo was collected, examined, and categorized based on what emotion is expressed. It can be concluded that Weibo users expressed anxiety, anger, happiness, fear and sadness during this crisis, and the editorial increased their emotional intensity.
\end{abstract}

Keywords: Social media, Emotions, China, Crisis communications, Weibo.

\section{INTRODUCTION}

The encounter between China and India border guarding military force has aroused attention within both countries and global range. Two sides of the army were involved in a fight against each other. The crisis, which happened in mid-June 2020 on the Galwan Valley border between Chinese and Indian territory, caused a dispute in both official authority channels and bilateral-civil debates online, social media in which provide these debates a possible platform. Since social media such as Facebook, Twitter, and Instagram are expelled from accessibility in China mainland, Weibo has grown to take the space those platforms absent from, and developed its equivalences in the Chinese market. Weibo, launched by Sina Corporation, has already become a social media platform with nationwide popularity among users [4]. Having more than 511 million monthly active accounts, this sizable user group can be sourced where researchers attain comprehensive understanding from [5].
Global Times is one of the top Chinese newspapers which has completed its success of making online voice via Weibo. On June 22, 2020, a Global Times Editorial, "India retreats from deals with China", was posted on Weibo via the Global Times account. As a reaction to the Sino-Indian border clash event, the editorial activated immediate feedbacks from Weibo users. The editorial accused the Indian government of giving their troops "complete freedom of action", which may cause Indian commanders not to be restricted in using firearms anymore. The editorial describes Modi's administration as "extremely irresponsible", and warns India that PLA would teach them a "good lesson" if the Indian fire the first shot. Despite the editorial takes a position that China is violated, assertive words haven't been avoided to show China's increasing power. For instance, "China's GDP is five times that of India", "most of China's advanced weapons are manufactured domestically" while "all of India's advanced weapons are imported", and 
"whoever fires the first shot will be wiped out by the PLA" [1].

There are research achievements within the area of how social media influence users' emotions. However, during the crisis, some common emotional layers expressed in comments through social media and how media content affects them still need to be further explored and explained. This paper tries to analyse comments of "India retreats from deals with China: Global Times editorial", @Global Times's Weibo post, to start this discussion. The author conducted the integrated crisis model and its revised version to analyse and categorize the emotions. As this model specifically focused on explaining emotions of anxiety, anger, fright, and sadness, during an organizational crisis, these emotions were likely to be experienced by the public in a crisis.

\section{THEORY FRAMEWORK \& LITERATURE REVIEW}

Previous studies have proved that public interaction and interpersonal communication on social media are encouraged by the sharing of emotion [6] [7]. As a medium platform, social media provides users online chambers for discussions, and each of these chambers is set for a certain topic.
Emotion could get interacted based on the materials posted by all the users toward a certain topic or event. As Xiong and Lv proposed, the users' emotion intensity follows the decrease of objectivity [8]. Comparing the content with more facts and the content with more attitude and opinions, the latter one is likely to arouse a more intense emotional reaction. Furthermore, emotions have also been argued as the "next frontier" in crisis research, by which strategy may be taken to be proactive in a crisis [9]. The integrated crisis mapping (ICM) model was introduced into the emotion research by Jin, Pang, and Cameron during a crisis [2]. The model aims to explain the possible emotional changes among people who participate and share common interests. Consisting of the public's cognitive and conative effort to manage a certain demand, the $\mathrm{x}$ axis is set as the public's coping strategy, while the $y$ axis shows the level of organizational engagement. Taking one country as an entity, the event of a conflict between two countries applicable the character of organizational crisis. Using the ICM model to frame this content analysis is reasonable and practical. As can be seen from "Figure 1", each of the four quadrants maps some types of crises with emotions predicted likely to be through by the public in this event learned from a social media channel.

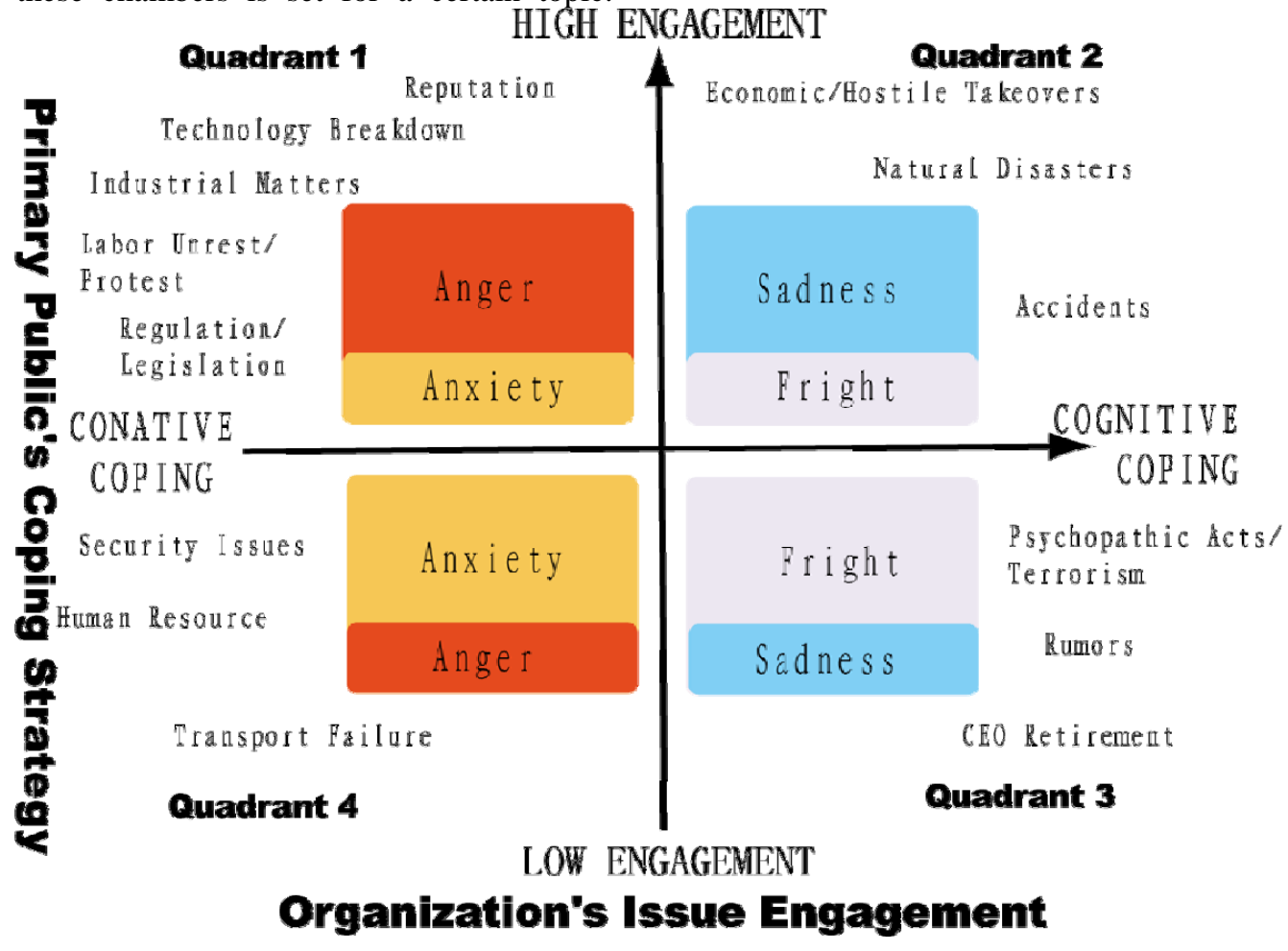

Figure 1 Integrated crisis mapping (ICM) model [2].

The definitions of emotions in the ICM model are a key point to be explained by the appraisal model of emotion. Arguably, anger, fright, anxiety, and sadness are emotions to be usually experienced by the 
public while a crisis is on-going. Lazarus defined anger as a "demanding offense against 'me' and 'mine'", fright as facing "uncertain and existential threat", anxiety as facing "an immediate, concrete, and overwhelming danger", and sadness as "having experienced and irrevocable loss" [10].

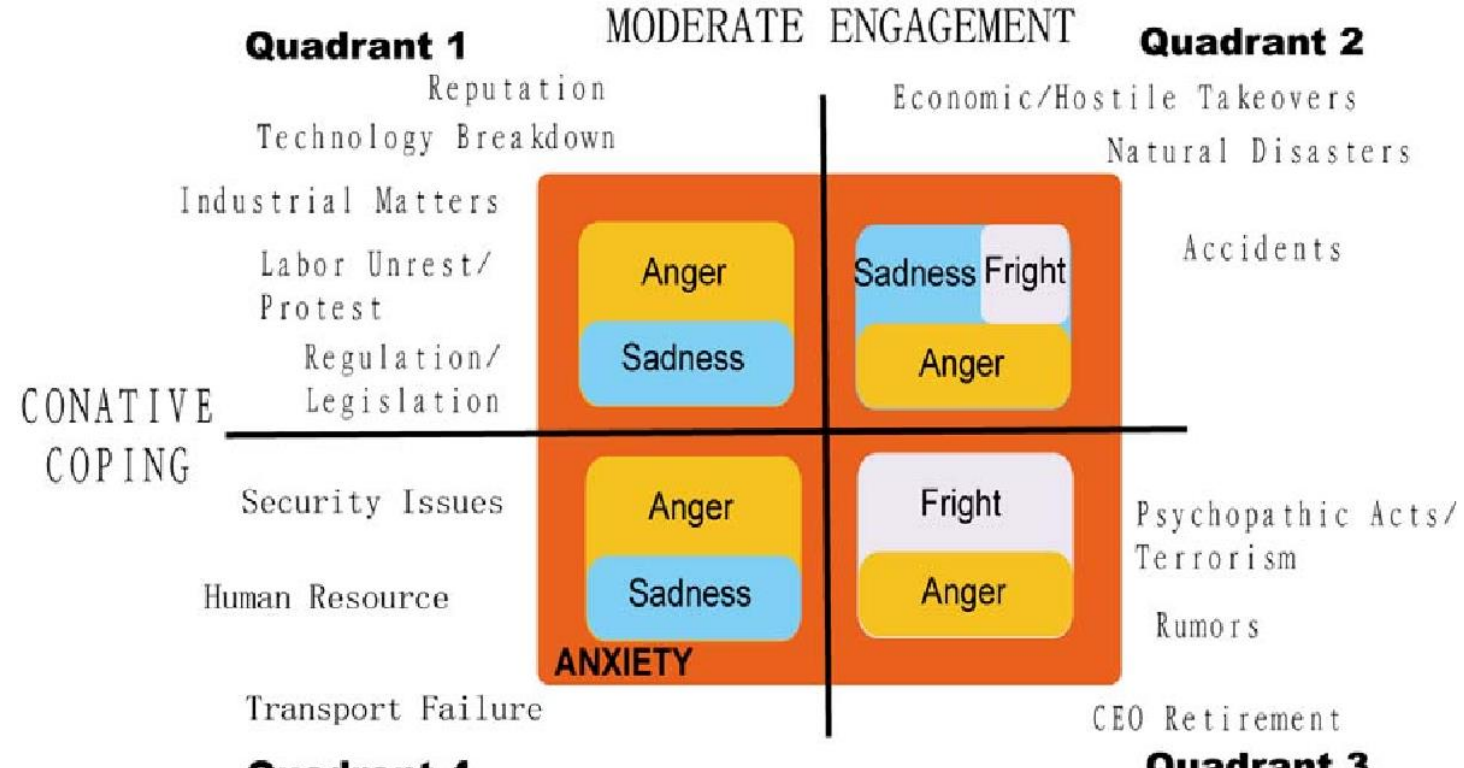

Quadrant 4

Quadrant 3

Figure 2 Revised integrated crisis mapping (ICM) model [3].

The ICM model was once revised based on a discovery that anxiety is appearing as an underlying emotion within multiple crisis situations. Anxiety is likely to coexist with other emotions [3]. Additionally, as shown in "Figure 2", in the revised ICM model, the anger, sadness, and fright are still fit the set in the previous ICM mode, but with readjustment in each quadrant.

This research expects to exam the emotions of the public as the audience of Global Times' Weibo post. It focused on the research question of what types of emotions were found in social media comments in the Global Times' Weibo post, "India retreats from deals with China: Global Times editorial". The ICM and the revised ICM model were used to give the researcher a frame for coding and categorizing each comment according to the emotion introduced in both of these models.

\section{METHOD}

The method conducted in this research has been proved to be efficient by Yeos, Pang, and Cheong. Moreover, content analysis is used in this study to examine comments posted by the public after reading "India retreats from deals with China: Global Times editorial" @Global Times's Weibo post. Since Weibo's nationwide popularity as a social media platform, the information is representative for further analysis and explanation [11].
Taking each comment as the basic sampling unit, there are 517 effective raw comments in total that were collected manually and achieved through Microsoft Excel. The standard of "effective" meant the comments have not been vanished by the poster and its information can be recognized by readability. All the comments before September 8th, 2020 were collected since there are hardly any discussions within the post thereafter.

The analysis aimed to try to give a result to the question of emotions launched by social media. As the ICM model gives four fundamental emotions the public likely to be experienced in the crisis, the comments were examined and categorized by the criteria of phrases and punctuation commonly used by Chinese speakers by anger, fright, anxiety, and sadness. For instance, keywords were used as the clues and basis for categorizing and giving further consideration to the context express, such as (a) anxiety: "what? Why?" "What should we do?" (b) sadness: "bad" "what a pity", (c) fright: "is it all right?" "no!", (d): anger "beat them!" "Let them know the consequences!". Based on the ICM model and coding strategies, the result of categorizing 517 comments was evaluated and analysed to see whether this model is capable of explaining the emotions influenced by crisis reported on social media. 


\section{RESULT}

To answer the research question, the result of the comments categorizing based on emotions are as follows. Taking 271 of the 517 comments, the statistic result indicated that anxiety $(52 \%)$ was the emotion which the public experienced the most. As the assumption this research made in advance, anxiety was followed by 142 comments of anger (27\%), 18 comments of fright (4\%), then 11 comments of sadness (2\%). Besides, another emotion category, which has not been considered in assumption, was concluded later based on the process of coding, that is happiness. It shared the rest of the percentage with the comments that just describe fact by 40 comments of happiness $(8 \%)$ and 35 comments which just show facts (7\%) ("Figure 3").

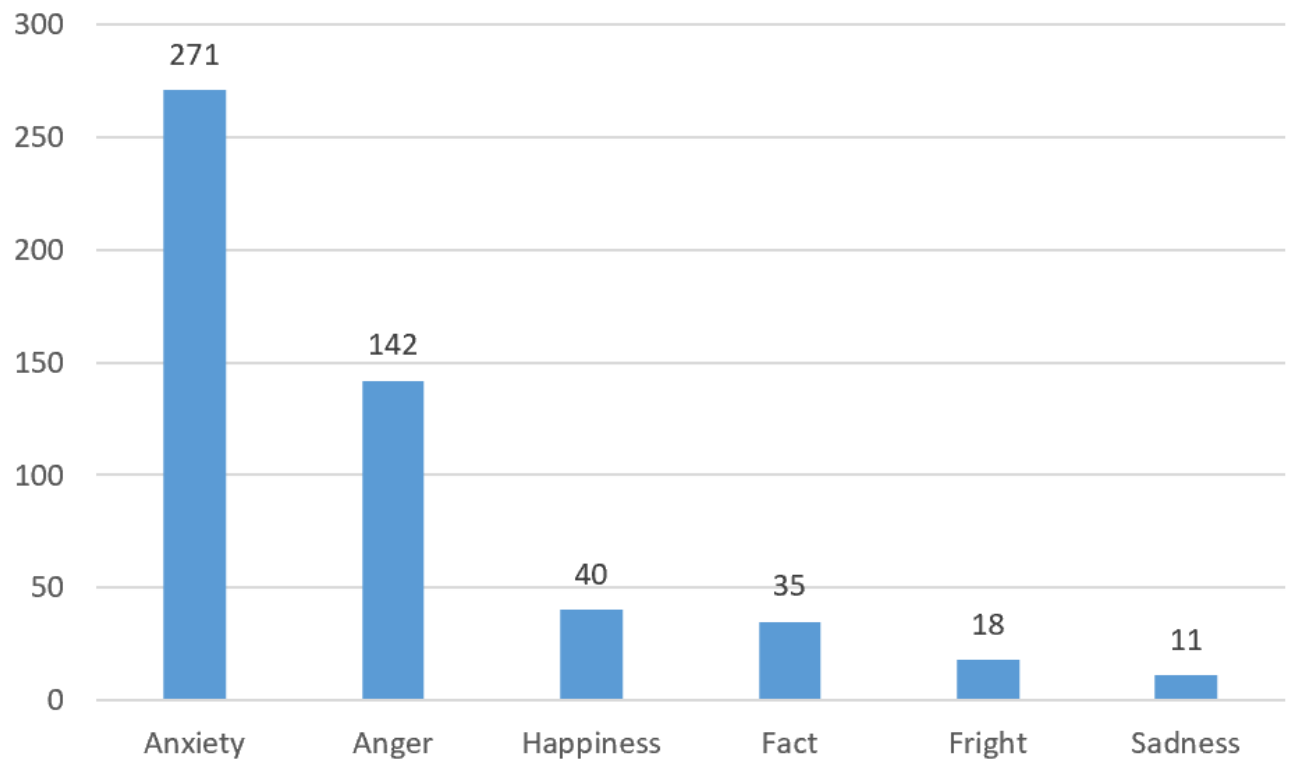

Figure 3 Breakdown of absolute numbers and percentages of the emotions expressed in all comments.

Weibo users expressed their anxiety by comments such as the following:

"Pay attention to safety, our soldiers."

"May China Peace, World Peace."

"Bros, India has nuclear weapons."

Anger was expressed by comments as follows:

"Who opens the first shot to the People's Liberation Army, who will be eliminated!"

"Speaking with rogue? Brain is a good thing!"

"Finish them!"

Happiness was the third-ranking emotions that expressed by the comments, contained messages like as follows:

"You make me confused, Hahaha."

"If the war start, directly attacked to New Delhi, Hahaha"

Fright was expressed such as the follows:
"It is difficult to deal with nuclear weapons."

Finally, Sadness is the least expressed emotion for the comments to the editorial, included the message such as the following:

"There is no way we are forced."

\section{DISCUSSIONS}

\subsection{Emotions Displayed by the Public During the Crisis on Social Media}

The revised ICM model suggests that anxiety plays a dominating role in the feedbacks from the Weibo users to this editorial [3]. Yeo et al. discovered that anger and sadness exist with anxiety simultaneously, while the basic emotion expressed on social media during a crisis is anxiety, followed by anger, fright, happiness, and sadness [11].

This study took a crisis on the country-level, the dominant emotion, anxiety, was followed by anger, happiness, fright, and sadness in descending order. There are similarities between the result in this paper 
and what found by Yeo et al. [11]. However, different from what they found, happiness was one place ahead in this case. Anxiety still played a dominant default role as the major emotion in this case, such as telling "our soldiers" to "pay attention to safety" or the hope of "China peace, world peace". As Weibo is a social media platform based on China market, its users include both Chinese citizens and those who share an interest with China. The editorial described the threat from India to China, which led users to feel the risk of their interest attached with the Chinese national security issue and sovereignty. Anger is the second most experienced emotion by the users who made comments to the editorial. For instance, "who opens the first shot to People's Liberation Army, who will be eliminated" and "finish them", represents the reaction of fighting back by the users when they felt the country they belong to was offended. Though Happiness was not considered by the ICM model, both this research and Yeo et al.'s research proved happiness is also the emotion that is likely to be experienced by the users in a crisis [11]. To be specific to this case, the reason of public felt happiness may relate to their expectation of Chinese increasing national power. By comparing India with China imaginatively, users may have established an optimistic expectation that China is much better than India, some tendency of teasing may also be contained. For instance, a user believes "if the war start", the Chinese military force could "directly attacked New Delhi". Through this kind of expectation, the ranking of happiness has been improved in this situation. Some users will feel worried because of the fighting in this crisis. Because they believe that India has military power, which may pose a threat to their country. In addition, the user who commented with sadness may be influenced by the concern of being involved in a war as a citizen of China and their helplessness. They posted comments like "there is no way we are forced".

\subsection{The Influence Put on Users' Emotion by Different Content on Social Media}

Xiong and Lv showed that the users' emotions will be influenced by the content through social media. Content with more objectivity would likely be reacted by less intense emotion, while content talk less about objectivity would be followed by much more intense emotion feedback from the audience [8].

In this research, the editorial mainly described opinions and positions from the Chinese point of view instead of fact. Hence, why comments by users were with such various and intense emotions including anxiety, anger, happiness, fright, and sadness was easy to be understood and explained. The editorial posted by @Gobal Times Weibo contained fewer words expressing objectivity, but much more words about opinions, attitudes, and assumptions, such as "warn India's feverish nationalists", "India needs to be held responsible for the possible consequences" [1]. Comments with strong emotions from Weibo users appeared correspondingly with these non-objective messages. It is difficult for getting these words out of the responsibility of arousing certain emotions.

\section{CONCLUSION}

This research analysed comments posted by Weibo users to @Global Times's post: "India retreats from deals with China: Global Times editorial". From the angle of emotion, all 517 comments have been evaluated. Besides the assumption, happiness also appeared as an important type of emotion during the crisis. The emotions were ordered in descending order as anxiety, anger, happiness, fright, and sadness. These were the emotions to be experienced in this case. The editorial encouragingly influenced user's emotions by giving non-objective content [8]. Social media users' emotion intensity was enhanced.

There were limitations in this study, only comments on Weibo were analysed. To fully understand the various voices and images that are communicated and spread online, future research may wish to further examine other social media platforms, such as Facebook, Instagram, WeChat, Tiktok, and so on. Nonetheless, this research is a good starting point for considering Weibo as a thriving social media platform in China.

Besides, the research can still be extended and may achieve further achievements. For instance, the discussion about the background of the China and Indian conflict may be more complete with support from the political science area. The research question would be answered from another angle, and the emotions can be evaluated with a certain phenomenon, such as online nationalism.

\section{AUTHORS' CONTRIBUTIONS}

This paper is independently completed by Haolong Yu. 


\section{ACKNOWLEDGMENTS}

Thanks to Professor Bernadette Wegenstein and her teaching assistant Chen Xiaobei for their inevitable guide and support in the media research area. Yvonne $\mathrm{Li}$ was also playing an important role in the completion of this research as the paper tutor. Without their support, this paper cannot be completed.

\section{REFERENCES}

[1] Global Times. (2020, June). Sina visitor System. https://weibo.com/1974576991/J7WdB3OjF?fro $\mathrm{m}=$ page_1002061974576991_profile\&amp;wvr =6\&amp; mod=weibotime\&amp;type=comment \#_rnd1616353557550.

[2] Jin, Y., Pang, A., \& Cameron, G. T. (2007). Integrated crisis mapping: Toward a publicsbased, emotion-driven conceptualization in crisis communication. Sphera Publica, 7. Retrieved from https://www.redalyc.org/pdf/297/29720421006. pdf

[3] Jin, Y., Pang, A., \& Cameron, G. T. (2012). Toward a publics-driven, emotion-based conceptualization in crisis communication: Unearthing dominant emotions in multi-staged testing of the integrated crisis mapping (ICM) model. Journal of Public Relations Research, 24 , 266-298. doi:10.1080/1062726X.2012.676747

[4] Weibo Data Centre. 2021. '2020 Weibo User Development Report'.

[5] https://data.weibo.com/report/reportDetail?id=4 56 (accessed on 13March 2021).

[6] Gan, C. (2020). Discourse on Europe's Migrant Crisis in Chinese Social Media: Recontextualising Nationalism and Defending Perceived Homogeneity. China Report, 56(1), 19-38.

[7] Correa, T., Hinsley, A. W., \& de Zuniga, H. G. (2010). Who interacts on the Web? The intersection of users' personality and social media use. Computers in Human Behavior, 26, 247-253. doi:10.1016/j.chb.2009.09.003

[8] Lin, H., Tov, W., \& Qiu, L. (2014). Emotional disclosure on social networking sites: The role of network structure and psychological needs.
Computers in Human Behavior, 41, 342-350. doi:10.1016/j.chb.2014.09.045

[9] Xiong, H., \& Lv, S. (2021, February). Factors Affecting Social Media Users' Emotions Regarding Food Safety Issues: Content Analysis of a Debate among Chinese Weibo Users on Genetically Modified Food Security. In Healthcare (Vol. 9, No. 2, p. 113). Multidisciplinary Digital Publishing Institute.

[10] Jin, Y., \& Pang, A. (2010). Future directions of crisis communication research: Emotions in crisis: The next frontier. In W. T. Coombs \& S. J. Holladay (Eds.), The handbook of crisis communication (pp. 677-682). Hoboken, NJ: Wiley

[11] Lazarus, R. S. (1991). Progress on a cognitivemotivational-relational theory of emotion. American Psychologist, 46, 819-834. doi:10.1037/0003-066X.46.8.819

[12] Yeo, S. L., Pang, A., Cheong, M., \& Yeo, J. Q. (2020). Emotions in social media: An analysis of tweet responses to MH370 search suspension announcement. International Journal of Business Communication, 57(2), 194-211. 